\title{
THE EFFECT OF AWKWARD POSTURE ON WORK-RELATED MUSCULOSKELETAL DISORDER AMONG HOSPITAL WORKERS IN PEKANBARU, RIAU
}

\author{
Raihanatu Binqalbi Ruzain \\ Faculty of Psychlogy, Islamic University of Riau
}

\begin{abstract}
BACKGROUND: Work-related musculoskeletal disorder may cause discomfort, work loss, and subsequently economic loss, in most industries, including hospital. Little is known about the effect of awkward posture on work-related musculoskeletal disorder. The study aimed to examine the effect of awkward posture on work-related musculoskeletal disorder among hospital workers.

SUBJECT AND METHOD: This was a cross sectional study conducted at a hospital in Pekanbaru, Riau. A sample of 205 hospital workers was selected at random for this study. The independent variables was awkward posture, measured by REBA method. The dependent variable was workrelated musculoskeletal disorder, measured by Nordic Body Map. The confounding factor was smoking status. The data were analyzed using multiple regression model.

RESULTS: As many as $82.9 \%$ of the hospital workers studied experienced mild work-related musculoskeletal disorder. As many as $17.1 \%$ of the hospital workers experienced severe work-related musculoskeletal disorder. After adjusting for the effect of smoking, awkward posture increased the risk 7 times as many of work-related musculoskeletal disorder, and it was statistically significant $(\mathrm{OR}=7.14 ; 95 \% \mathrm{CI}=2.93$ to 17.36; $\mathrm{p}=0.001$ ).

CONCLUSION: After adjusting for the effect of smoking, awkward posture increased the risk of work-related musculoskeletal disorder. Hospital workers with awkward posture need special attention as they are at higher risk of experiencing work-related musculoskeletal disorder.
\end{abstract}

Keywords: awkward posture, work-related musculoskeletal disorder 